\title{
Learning actions indicating algebraic thinking in multilingual classrooms
}

\author{
Helena Eriksson ${ }^{1,2}$ (D) Inger Eriksson ${ }^{3}$ (D) \\ Accepted: 27 October 2020 / Published online: 8 December 2020 \\ (C) The Author(s) 2020
}

\begin{abstract}
This article discusses algebraic thinking regarding positive integers and rational numbers when students, 6 to 9 years old in multilingual classrooms, are engaged in an algebraic learning activity proposed by the El'konin and Davydov curriculum. The main results of this study indicate that young, newly arrived students, through tool-mediated joint reflective actions as suggested in the ED curriculum, succeeded in analysing arithmetical structures of positive integers and rational numbers. When the students participated in this type of learning activity, they were able to reflect on the general structures of numbers established as additive relationships (addition and subtraction) as well as multiplicative relationships (multiplication and division) and mixtures thereof, thus a core foundation of algebraic thinking. The students then used algebraic symbols, line segments, verbal, written, and gesture language to elaborate and construct models related to these relationships. This is in spite of the fact that most of the students were second language learners. Elaborated in common experiences staged in the lessons, the learning models appeared to bridge the lack of common verbal language as the models visualized aspects of the relationships among numbers in a public manner on the whiteboard. These learning actions created rich opportunities for bridging tensions in relation to language demands in the multilingual classroom.
\end{abstract}

Keywords Algebraic thinking El'konin-Davydov curriculum - Learning activity· Relationships Multilingual classrooms

Helena Eriksson

hei@du.se

Inger Eriksson

inger.eriksson@hsd.su.se

1 Department of Education and Learning, Dalarna University, Falun, Sweden

2 Department of Mathematics and Science Education, Stockholm University, Stockholm, Sweden

3 Department of Humanities and Social Sciences Education, Stockholm University, Stockholm, Sweden 


\section{Introduction}

The overall interest of this article is to exemplify and discuss how learning activity suggested by Davydov (1990) can enhance algebraic thinking through collective tool-mediated reflections in a multilingual classroom in Sweden, as students explore positive integers and rational numbers.

When teaching mathematics to the youngest students, everyday language and everyday experiences are often used to illustrate mathematical concepts (Adler, 2019). This type of teaching has proven to be problematic since mathematical concepts are theoretical (i.e., scientific) and therefore not accessible through everyday language or everyday actions (Davydov, 1990). This sort of teaching is especially challenging in multilingual classrooms (Adler, 2019; Campbell, Adams, \& Davis, 2007; Hansson, 2012), since the participants - the students and teachers - have different experiences regarding culture, language, and mathematics (Campbell et al., 2007; Norén, 2015). Further, research in multilingual classrooms also shows that teaching using mediators (tools that manifests scientific knowledge) and that enables code switching (switching between languages) and transparency (visualising the use and the meaning of specific tools) enhance mathematical concepts (Adler, 2001). In addition, there are arguments that teaching mathematics in multilingual classrooms should be organised as joint activities with tasks aimed at a high cognitive and theoretical level (Lantolf \& Zhang, 2017; Moxhay, 2008; Storch, 2017). Thirdly, transparency such as joint collective actions with the use of mediating tools in well-organised teaching situations is vital when teaching in multilingual classrooms (Storch, 2017). These types of actions are addressed in Davydov and El'konin (the ED curriculum) specially-designed activity for instructions - the learning activity_aiming at theoretical thinking.

Learning activity is strongly associated with ideas on collaborative or joint exploration of abstract or structural aspects of an object of knowledge (Giest \& Lompscher, 2003; Rubstov, 2013; Zuckerman, 2004). The aim of developing theoretical thinking is connected to the process of ascending from the abstract to the concrete (Davydov, 2008) which in mathematics may be related to algebraic thinking (cf. Bourbaki, 1974; Davydov, 2008; Krutetskii, 1976). Within the research field of early algebra focusing on algebraic thinking in relation to the youngest students, the ED curriculum is often referred to as a promising way of developing generalisations and theoretical mathematical thinking (Gutierrez, Leder, \& Boero, 2016; Kieran, 2018; Kieran, Pang, Schifter, \& Fong Ng, 2016). In such activity, speciallydesigned tools - learning models - are used as means of enabling transparency as they mediate, capture, and visualise the abstract theoretical (general and structural) content of, for example, mathematical concepts of knowledge (Arievitch \& Stetsenko, 2000; Davydov, 2008; Moxhay, 2008).

Considering the issues indicated above and related to the current situation in which many classrooms are multilingual, we wish to contribute to the discussion of issues regarding the development of algebraic thinking. The question we would like to pose concerns how learning activity, with its concepts of learning actions, learning models and collective reflections, can facilitate algebraic thinking regarding positive integers and rational numbers in whole-class discussions with young students (6 to 9 years old) in multilingual classrooms.

\subsection{Aim and research questions}

The aim of this study is to exemplify and discuss young (age 6 to 9 years) students' reflective actions indicating emerging algebraic thinking when they participate in a multilingual learning activity concerning integers and rational numbers. Specific to these students is that they are 
newly arrived in Sweden and have different mother tongues and different mathematical experiences. The research questions guiding the analyses are:

- What actions indicate algebraic thinking among these young students when they reason around positive integers and rational numbers in lessons designed as a learning activity in which learning models are used as mediating tools?

- What indicates that the learning models used in the students' collective reflections are enhancing mediation and transparency and thus bridging insufficient language skills in relation to Swedish?

The article is structured as follows: in Section 2, we present algebraic thinking and some cornerstones of learning activity theory. Two research lessons and their analyses are presented in Section 3. Results related to algebraic thinking and learning models respectively are presented in two interrelated sections, and in Section 6, implications for teaching in multilingual classrooms are discussed.

\section{Background}

We first outline student work on relationships between quantities as one example of algebraic thinking. Then, we present three features of learning activity-learning actions, learning tasks, and learning models - in order to understand the mediation and transparency of joint reflective learning actions.

\subsection{Algebraic thinking}

Algebraic thinking is often focused on functional thinking, generalisation of patterns, and work on variables (Blanton et al., 2019; Gutierrez et al., 2016). Developing algebraic thinking and number sense of young students, 5 to 12 years old, may also be connected to the analysis of arithmetical structures as a foundation of algebra (Carraher \& Schlieman, 2007; Kaput, 2008; Kieran et al., 2016; Radford, 2014; Venenciano \& Heck, 2016; Warren, Trigueros, \& Ursini, 2016). A complementary explanation of algebraic thinking states that the core of algebraic thinking is the analysis of relationships (Bourbaki, 1974; Davydov, 1982; Krutetskii, 1976). As an example, in algebraic work, analyses of structures may focus on relationships within arithmetic using both letters and number symbols, not just as operations with specific numerical examples (Kaput, 2008). In such analyses, the meaning of the equal sign is in focus instead of using it as an operation sign (Kieran, 2018). Another way of explaining algebraic thinking related to arithmetic structures is to describe the character of this type of thinking. Algebraic thinking can thus be explained as operations with unknowns, including operations with variables and with parameters. One example is to analyse mathematical situations using unknowns (Radford, 2014). The character of actions may also be explained as modeling relationships among quantities represented by alphanumeric signs. Finally, spoken language and gestures can be used to specify explorations of mathematical situations (ibid.).

In the ED curriculum, algebraic thinking is grounded in measurements of quantities (Freudenthal, 1975; Schmittau, 2003). Ideas are based on human cultural and historical needs to measure "the world", to compare and to make unequal quantities equal (Davydov, 2008). Further, the ED curriculum is founded on the idea that all numbers constitute structures of 
additive relationships (including addition and subtraction), and multiplicative relationships (including multiplication and division) (Davydov, 1982; see also Kieran, 2018; Yeong \& Dougherty, 2013). In an additive relationship, each pair of numbers constitutes a third number assigned as $a+b=c$, and therefore also for example $c-b=a$. A multiplicative relationship of whole numbers follows the complex relationship of $a \times b=c$, and $c / b=a$ for $b \neq 0$. Foundations of algebra can, through these relationships, be used by students to analyse structures within arithmetic (Davydov, 1990). Identifying student actions when they are analysing relationships and structures may thus be used to identify and describe algebraic thinking.

\subsection{Learning activity}

The ED curriculum is closely connected to the concept of learning activity based on Vygotsky's (1978) cultural-historical theory and Leont'ev's (1978) activity theory (Davydov, 2008). First, following Vygotsky, theoretical or scientific thinking can be understood as higher order thinking, which contrasts with everyday thinking grounded in everyday empirical experiences. Because of its nature, theoretical thinking is necessary to be discerned and understood through the use of subject-specific tools (learning models) developed through actions (learning actions) in content-rich learning activities (Morris, 2000; Schmittau, 2003, 2011). If students can identify specific core principles or a theoretical aspect of an object of knowledge, an artefact-symbol or model — can exemplify and be used in the further exploration of concrete instances of theoretical knowledge, described as ascending from the abstract to the concrete (Davydov, 2008). Second, the aim of the joint actions in a learning activity is the development of student agency, that is students' capacity to act and participate in new and independent ways in different activities (Davydov, 2008; Repkin, 2003; Rubstov, 2013). All student voices are important when teaching is aimed at creating collective reflection on the theoretical aspects of an object of knowledge (Bakhtin, 1981; Davydov, 2008). The development of a learning activity consisting of learning actions and learning models may make the mediation of a piece of theoretical knowledge more transparent which can be compared to as what Lantolf and Zhang (2017) and Storch (2017) referred to as scaffolding important for students in multilingual classrooms.

\subsubsection{Problem situations_-planning a learning activity}

One precondition for enabling learning activity is the design of the initial problem situation in which the object of knowledge is embedded (Repkin, 2003). Through social and cultural historically developed capacities, students need to analyse the problem situation to identify a problem worthwhile of study and to formulate a learning task to be solved. When the students analyse the problem situation, they presumably have an idea of the problem to be solved from their previous work (Davydov, 2008). In addition, they have to reflect on the actions they can take and the tools they can use to solve the problem (Repkin, 2003). Throughout this work of problem identification and evaluation of previous knowledge, the students should be able to identify contradictions, thus things that are unexpected or that are a struggle for them. These contradictions can be understood as an opportunity to move the process of learning. The idea is that the students will be conscious of the limitations of their knowledge and thus the need to learn is evoked. 


\subsubsection{Learning actions-realisation of a learning activity}

A learning activity is realised through its object-oriented and tool-mediated actions (Davydov, 2008; Repkin, 2003). These object-oriented actions are described as learning actions, which follow a specific, theoretically informed pattern to engage students in high-quality conceptual, theoretical knowledge (Davydov, 2008). These actions follow a pattern which can be described in short as accepting or posing the task, identifying a problem including the object of knowledge, transforming the conditions of the task in order to model general relationships, transformations of the model, construction of new tasks, assessment of model (learning model), and, finally, evaluation of the general essence of the object of knowledge (Davydov, 2008).

\subsubsection{Learning models-tooling the learning activity}

In learning activity, the idea of mediating tools follows Vygotsky's idea of tool-mediated actions. One way of manifesting such tools is the construction of learning models (Arievitch \& Stetsenko, 2000; Davydov, 2008; Gorbov \& Chudinova, 2000). A learning model should make it possible for students to agentively and jointly explore, identify, and argue about the theoretical aspects of an object of knowledge (Davydov, Slobodchikov, \& Tsuckerman, 2003; Zuckerman, 2004). Learning models should capture human historical development through the mental processes that are embedded, transformed, and internalised in them as cultural tools (Arievitch \& Stetsenko, 2000; Davydov, 1982). Theoretical aspects built into a learning model may take a graphical, symbolic, or physical form, with the use of written and verbal language and gestures to make them more explicit (Davydov, 2008). Built into the learning model are the aspects of an object of knowledge to explain and visualise/materialise these aspects (Eriksson et al., 2019).

One example of learning models given by the ED curriculum involves those for additive relationships shown in Fig. 1.

In the ED curriculum, learning models are introduced in the early grades in relation to the measurement and analysis of quantities (Davydov, 2008; Izsák \& Beckmann, 2019; Schmittau, 2003; Yeong \& Dougherty, 2013). The quantitative properties of an object can be represented by, for example, letter symbols or a learning model in the form of line segments (Fig. 1). When measuring and analysing quantities with the help of the line segments, the meaning of the equal sign becomes central and possible for the students to discern (Davydov, 1982, 2008). In an example, presented by Schmittau (2003), the students compare the lengths of two tables and symbolise them as $A$ and $B$. The relationship between them is represented as $A=B, A \neq B, A>B$, or $A<B$. There is no need for numbers during this work, instead the letters represent quantities and the models are the result of these measurements. Thus, a learning

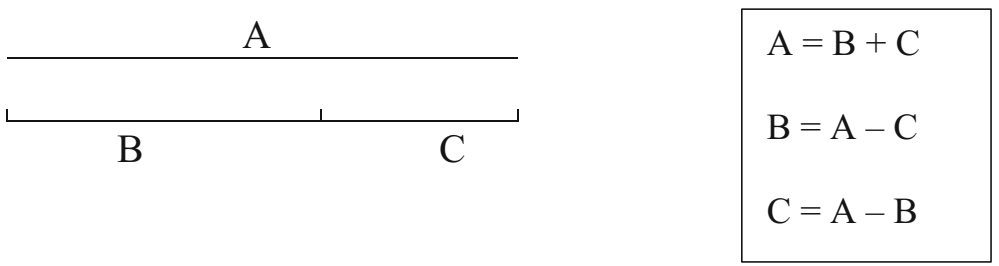

Fig. 1 Examples of learning models visualising the additive relationship (Davydov, 1975) 
model enables the analysis of universal (abstract) relationships within an object of knowing (Arievitch \& Stetsenko, 2000; El'konin, 1999). The tools are not primarily to be used for simplifying calculation but as psychological tools to analyse relationships between, for example, different quantities (Davydov, 1982, 1990, 2008; Schmittau, 2003). Based on the theoretical implications given, student object-related learning actions are of particular interest to identify and analyse how details of an object of knowledge are dealt with, or to put into the words of Radford (2015), when the potentiality of an object of knowledge is set in motion.

To summarise, our theoretical foundation is that a learning activity revolves around a problem situation evoking student learning actions directed at the construction and elaboration of a learning model. A learning model consists of, for example, algebraic and numerical symbols or graphical models. The learning model helps the students to make theoretical dimensions of knowledge transparent, for example, they may help the students to analyse relationships between quantities that also can be understood as an algebraic way of thinking. In the next section, algebraic thinking and learning activity are used as frameworks for designing and analysing teaching.

\section{Method}

In the following, first, the data used in this article are presented, then the tasks the students were working with. Finally, an account of the analysis method used and some ethical considerations are given.

\subsection{Data}

The data used in this article were chosen from a collaborative research project aimed at exploring the ED curriculum in a multicultural educational context in Sweden (cf. Eriksson, 2015). From this project, two research lessons were chosen: one lesson from grade 1 involving 18 students ( 6 to 8 years old) and one from grade 2 involving 23 students ( 7 to 9 years old). The school participating in the project is multilingual and multicultural, so a high proportion of the students were second language learners of Swedish. Approximately twenty to twenty-five mother tongues were spoken at the school. According to national and local screening mathematics tests, abilities varied in the groups of students. The young students were not familiar with mathematical concepts either in Swedish or in another language.

The six teachers and the teacher researcher (the first author of this article) were all qualified teachers and had 1 to 10 years of teaching experience. The first author participated in the lesson design and was responsible for the video observations that form the main data. The camera was placed behind the students at the back of the classroom to provide data on actions expressed through speech, gestures, and writing on the board during class discussions.

The films were transcribed capturing students and teachers at work. The transcripts of the films have been translated into English according to the principles of conventional written communication. This means that some of the students' linguistic challenges are not as prominent as they were in the classroom situation. In these transcripts, the names of the students are fictitious and only the teacher and the first author have access to the name key.

All the parents had given their written consent for their children to participate in the project following the standards of the Swedish Research Council (Vetenskapsrådet, 2017). Since most of the students in the project were newly arrived in Sweden, this agreement and other 
information about the project were described to the parents at meetings by mother-tongue teachers and interpreters.

\subsection{The design of tasks and their introduction to the students}

In this section, we briefly present the problem situations underlying the results in Sections 4 and 5. The overall goal of the lessons was to explore positive integers and rational numbers by constructing models regarding relationships among the numbers. The object of knowledge was inequalities to be transformed into equalities based on measurements to reveal such possible relationships (cf. Davydov, 1975, 1982). The task designs were inspired by Davydov, Gorbov, Mikulina, and Saveleva (2012). Data analysis was based on three examples of object-oriented action sampled from two different lessons. In the first example, grade 1 student actions on addition were used; in the second example, the work on subtraction in grade 2. The third example (again from the same lesson in grade 1) used student actions comprising division, addition, and subtraction.

\subsubsection{Transformations using addition-grade 1}

The students in grade 1 were to collaboratively construct a tentative model of two different quantities of cubes that were placed on a table. They drew a long line segment on the board representing the larger quantity of cubes and a short line segment for the small quantity (Fig. 2a, b).

After the construction of a first tentative model, the students were challenged to construct equality between the two quantities. They were to find ways of achieving addition and subtraction, by adding one more cube for addition and taking one cube away for subtraction. The action on addition is used as an illustration in the results (see Section 4.1).

\subsubsection{Transformations using subtraction-grade 2}

In order to illustrate the work on subtraction, an example from a lesson in grade 2 is given in which the students and their teacher were discussing the relationships between three different quantities: $A, B$, and $C$ drawn on the board (see Fig. 4 further down). The quantities on the board were presented as the line segments of a potential learning model. The discussion was staged as a joint reflection about the relationships (also presented in Fig. 1). First, these quantities were related to each other according to the equality $A=B+C$. The section in the results is about the representation of the length $C$ using the lengths $A$ and $B$ (Section 4.2).

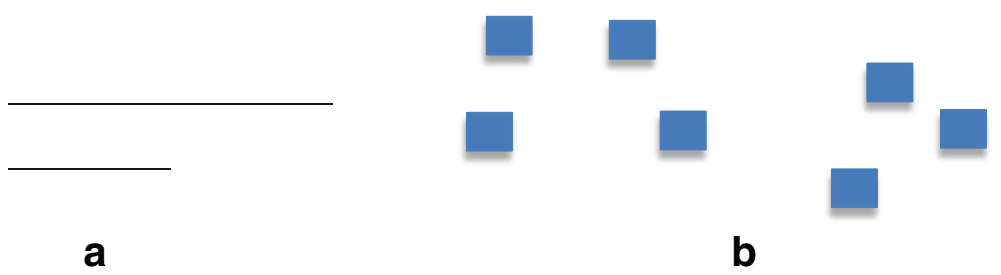

Fig. 2 Reconstruction of student work. a The line segments the student constructed on the board. b The piles of cubes placed on the table in front of the students 


\subsubsection{Transformations using division, subtraction, and addition-grade 1}

In the same grade 1 lesson presented above, the task was changed to further challenge the students. The qualified task started in the same situation as in Fig. 2a, b, but now, the students were to construct equality without adding or taking anything away from the total of the two quantities. The students were expected to elaborate the line segments to divide the difference between the two lengths into two halves and then subtract one part from the long length and add it to the short length (Section 4.3).

\subsection{Method of analyses}

The focus of the analysis was student learning actions reflecting on relationships between quantities. The analysis included several steps. In the first step, a chronological narrative description of each of the three chosen lessons was constructed led by questions, such as: "Who is doing what with which goal? And with the help of which tools?" The narrative focused on student and teacher joint actions during the wholeclass discussions comprising verbal language, and gestures-especially those related to learning models, such as how they were pointing and writing and drawing on the whiteboard (Roth \& Radford, 2011). These narratives were illustrated with excerpts from the lessons. When analysing these complemented narratives, student (and teacher) tool-mediated and goal-directed actions related to the object of knowledge were identified (Davydov, 2008; El'konin, 1999). In a next step, the actions that transformed inequality into equality were identified (Davydov, 1982; Yeong \& Dougherty, 2013). These transformations were also identified in relation to (a) who initiated the work (Gorbov \& Chudinova, 2000), (b) what the models were used for (Arievitch \& Stetsenko, 2000), (c) the modeling of the problem situation, what aspects it illustrated (Davydov, 1990, 2008; El'konin, 1999), and (d) where it was staged (Eriksson et al., 2019). In a final step, possibilities for multilingual classrooms-high level cognitive work (Storch, 2017), mediation, and transparency (Adler, 2001)-were analysed related to the pattern of learning actions suggested by Davydov (2008), thus how the students accepted the task, identified the problem, modeled the general relationships, transformed of the model, constructed new tasks, and discussed the model related to general essence of the object of knowledge.

The results are presented in the following two sections. First, in Section 4, the analysis of student object-oriented actions indicating algebraic thinking is presented and, second, in Section 5 , the analysis deals with how learning models are used by students to overcome their insufficient verbal language abilities.

\section{Actions on learning models indicating algebraic thinking}

All tasks were framed in a problem situation concerning an inequality to be transformed into an equality. The transformative work of the students was achieved through toolmediated and object-oriented learning actions. These actions were identified as relationships between quantities, here illustrated in three sequences based on the relationships in focus (a) actions of addition, (b) actions of subtraction, and (c) actions of division, addition, and subtraction. 


\subsection{Actions of addition}

When presented with the problem situation in Fig. 2a, b, the students initially suggested that equality could be made by using a larger quantity as a reference. A student (Mohammed) put one more cube into a group with fewer cubes, thus $A+B=C$ when $C>A$. However, when Mohammed started to also change one of the two-line segments that were written (Fig. 2) on the board, his classmates protested.

\section{Excerpt 1}

06:00 The teacher: How to make this equal?

06:09 [Mohammed is standing by the table with the cubes. Without saying anything he added another cube to the pile of three cubes. He grabs the pen and starts to manipulate one of the two-line segments on the board. But before he had managed to complete his drawing several of the other students protested]

06:15 Nadiro: No, another kid can do that.

06:24 [Yosuf goes to the whiteboard. He takes the eraser. Some students rise from their chairs. Yosuf puts the eraser back again. Instead, he takes a pen and starts to extend the shorter line segment. The other students sit down again. By extending the shorter line, he makes both lines equal]

06:39 Hana: But they are not the same. Here it looks as if there are many of them [she points at the pile with in which the cubes are far away from each other], and here there is just a few [she points at the pile in which the cubes are close to each other].

06:41 Mahad: But are they not the same?

06:41 Teo: There are four here and four here.

06:41 Nadia: Yes, they are.

06:44 The teacher: And, then they are the same. What did we do?

07:00 From the students: Added, put together, adding, plus.

When Mohammed put the correct number of cubes into the physical pile, none of the other students reacted. However, when he started to construct equality by manipulating the line segments on the board, the other students joined the discussion. The action on the line segments engaged the students to reflect on how equality was constructed. Yosuf who joined Mohammed at the board first took the board eraser, but then slowly put it down again. It looked like he had intended to erase something, thus to subtract. After hesitating, he instead added a length to the short line segment to make the line segments equal. Here, $C-B=A$ was changed to $A+B=C$. In this transformation of an inequality into an equality, the student created an additive relationship and implicitly determine one essential and general property of numbers; all quantities can be represented as additions of other quantities. They managed this without using any formal mathematical language. Compared to an algebraic way of thinking, the students analysed this relationship without using numbers, but operated with the quantities involved by using the line segments as a learning model to construct an equality (Fig. 3).

\subsection{Actions of subtraction}

Earlier during this lesson, the students had agreed that $A=B+C$ is the same as $A=C+B$ and also that $B=A-C$ represents the same relationship. These relationships were argued with help of the model written on the board (Fig. 4).

The following excerpt illustrates a discussion of how to represent $C$. 
a

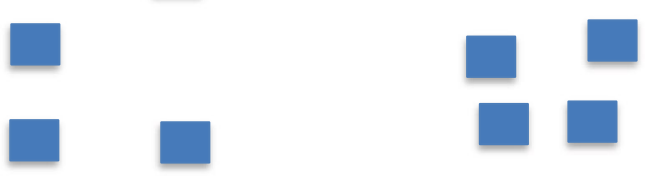

\section{b}

Fig. 3 a The two-line segment drawn on the board as a result of the students' construction of an equality. b The cubes placed on the table are illustrated

\section{Excerpt 2}

07:15 Ramin: We also have $\mathrm{C}=\mathrm{B}-\mathrm{A}$. [writes the relationship from right to left. He begins with the symbol of $\mathrm{A}$ then the symbol for subtraction, the symbol for $\mathrm{B}$, then equals and the last symbol, C.]

07:35 The teacher: hmmm, just a moment. How to explain this?

07:40 Rashad: A minus B, that gives us C [explaining in the same order that Ramin had written the relationship]

07:45 Ramin: Knowing A [pointing at the line segment named A on the board (Fig. 5a).] and taking B away [pointing at the line B on the board (Fig. 5b)], $\mathrm{C}$ is left. [now pointing at line $\mathrm{C}$ on the board (Fig. $5 \mathrm{c}$ ) and finally pointing at his written model in which he used algebraic symbols on the board, in the direction from right to left.]. A... taking B... away... is the same as C.

07:55 The teacher: hmmm, how to explain this. We have two suggestions. Two different suggestions. What two different suggestions do we have?

08:10 Mohammed: It is to take away; it is like minus.

The teacher: That is what we want to discuss. How to take away? What different suggestions do we have?

The students and the teacher agreed that the quantity named $C$ could be explained by the relationship between $A$ and $B$. The students constructed an equality by taking the segment $B$ (Fig. 5b) away from segment $A$, leaving a line segment equal to length $C$ (Fig. 5c). For this construction, the students used the line segment model in combination with the algebraic symbols. The line segments were used as a model in a relevant manner, the smaller $B$ was taken away from the long line $A$. The model comprising the algebraic symbols were verbally
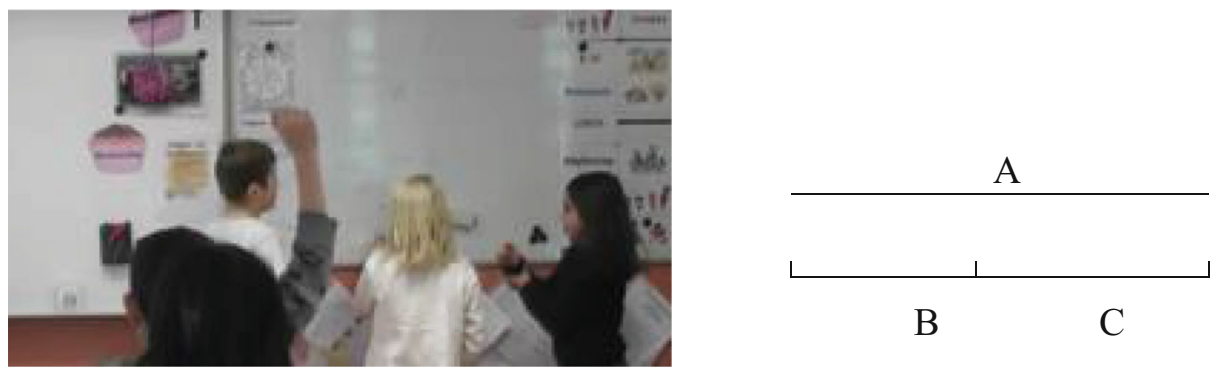

Fig. 4 Students discussing the relationships on the board and a reconstruction of the model 


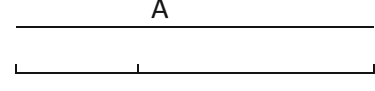

B

$\mathrm{C}$

a

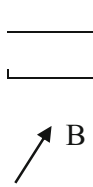

A

C

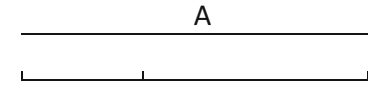

B

b

C

Fig. 5 a-c The arrows show how the students were pointing at the line segments

argued in an accurate manner, but the written notation was wrong. The student noted $C=B-A$ in the direction right to left, thus applying the direction of reading Arabic which is these boys' mother-tongue. This way of writing the statement meant that the students missed that the minuend should be noted as $A$ and the subtrahend should be noted as $B$. The theoretical aspect of non-commutative property regarding subtraction was lost in the linguistic actions (as reading it from right to left). But the three ways of modeling, the line segments, the algebraic symbols, and the verbal language worked together as a learning model to highlight this. The teacher joined in the discussion and highlighted that this type of statement must be read from left to right. However, the learning model with the algebraic symbols and a discussion of the importance of the reading direction signalled this general property regarding subtraction. Compared to an algebraic way of thinking, the students reflected on these relationships and analysed the structure of unknown quantities by using algebraic symbols and the line segment model. The work on the line segment model and the algebraic symbols highlighted the convention of the direction of reading.

\subsection{Actions of division, addition, and subtraction}

In a different problem situation, the grade 1 students, who had earlier constructed an equality through actions of addition, were now supposed to make an equality without taking away or adding any cubes to the total quantity of the two piles. A discussion of how to construct equality given these restrictions occurred among the students:

\section{Excerpt 3}

12:25 [The teacher makes two new piles of the cubes, one pile of three cubes and the other one of four cubes] How to construct equality, and not add or take anything away?

13:15 [Rima goes to the table and takes one cube from the pile of 4 cubes]

13:20 Another student: But....

13:25 Pele: This is not possible... This cannot be equal if we do not exclude or add something. Making equality is...

13:40 Hamza: But, wait... in the model... [points at the whiteboard].

13:55 The teacher: How can this be done in the model?

14:35 [Bea goes to the whiteboard and erases a part of the shorter line segment.]

14:36 Hamza: No, wait a minute... Let it be....

14:50 [The teacher draws the shorter line segment back again.]

15:10 Halil: He took from the big group [of cubes].... But in the model, we can do it equally [the student goes to the board]. 

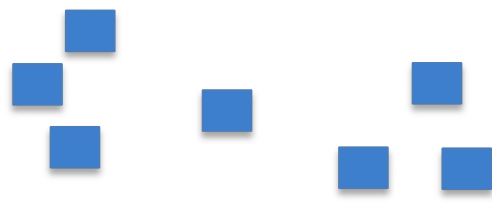

Fig. 6 The two-line segments when Halil first divided the difference (indicated by the three arrows)

15:21 [Halil erases a part of the longer length (Fig. 6).] If we take away just a piece. [he "took" the part of the longer line segment with the three arrows and added "the length between two of them" to the smaller length. He used his fingers to show that it was the same length he had erased; thus, this part was divided in two halves (Fig. 7).]

16:00 Hamza: We can only do this [creating an equality] in the model [but not with the cubes].

In Excerpt 3, the students analysed the given problem situation and it did appear to challenge them; no one could argue verbally how to construct equality given the new conditions. Together, they noted that equality had to be constructed with an act of transformation other than addition or subtraction. Using the line segments, they divided the difference between the two quantities into two parts (mathematically correct into two halves) and then "moved" one of these two parts (halves) to the shortest line segment. Since the teacher had chosen an odd number of cubes, it was only possible to solve the problem using the line segments model. As previously, the students did not use formal mathematical language. In this situation, Hamza highlighted that it was only possible to solve the problem in the model. Implicitly, he argued that it is possible to carry out more general actions by using the line segments than by using the physical artefacts. In relation to algebraic thinking, the students were using the models to analyse and understand the multiplicative relationship (division of the difference into two halves, or in this study to divide the difference between two quantities) and the additive relationship including addition and subtraction.

In Fig. 8, the different learning actions are summarised. In this figure, the common problem situation of a case of an inequality and the different learning actions the students used to create an equality are depicted.

The teacher established the problem situation of inequality and asked the students to construct line segments modeling this inequality on the whiteboard. Based on this model, the students initiated a joint modeling activity aimed at constructing equality. The modeling work used to analyse the situation was done in a more general manner than comparing numerical examples only; it was carried out in what can be understood as an algebraic way of thinking. In grade 1, the model was used by the students to enhance an argument that the line segments represented the same quantity (the same length) by adding a length to the shorter line. The line segments visualised equality; thus, the physical objects in the two piles were placed far apart and close to each other, the proof of
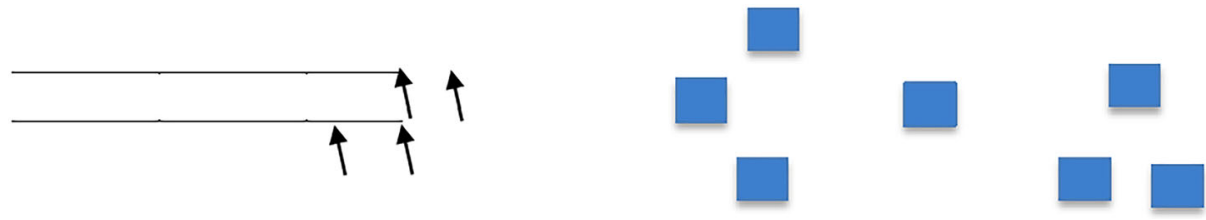

Fig. 7 The two-line segment, when Halil has subtracted the long top line and added the part he took away to the shorter line below (indicated by the two arrows) 


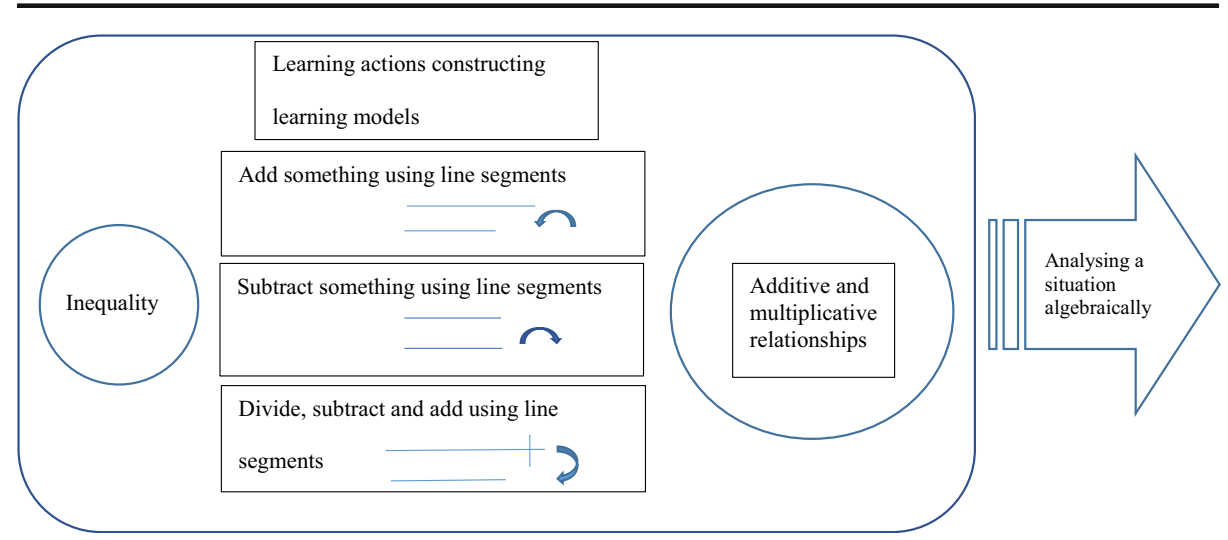

Fig. 8 Illustration of the different learning actions indicating algebraic thinking

subitising. This can be seen as an example of a contradiction manifested in the lessons that drive the students' discussion. In grade 2, the way the students used the line segment model and the algebraic symbols created a situation in which the non-commutative property of subtraction had to be highlighted by the teacher. In another example from grade 1 where the problem situation contained an odd quantity of cubes to be transformed into equality, the students realised it was possible to achieve equality only by transforming the line segment model.

\section{Actions on learning models bridge tensions caused by verbal language}

From student actions with the learning models, we highlight four aspects that appeared to bridge the insufficient common verbal language and/or common mathematical experience among the students. It seemed that these actions made the student transformations of inequality to equality transparent for the class and made it possible for them to reason algebraically.

First, when a problem situation was established in the lessons, the students could engage in joint analytical work. It seemed that the actions on the physical objects such as the cubes and the line segments model created a common space of experiences for the elaboration of the equality.

Second, the joint modeling staged on the white board enabled the students to reflect on each other's actions. The public work on the models visualised and specified the object-oriented actions of one student in a way that the other students could follow and reflect upon. One example to highlight is the joint construction of the line segments when the students in grade 1 explored the actions of addition and subtraction. Many of these joint actions were conducted without verbal language. When one student was to represent an addition using the line segments, he started to erase a length from the longer line. The other students protested by standing up. They immediately sat down again when the student put down the eraser. It seemed that the visualised elaboration of the learning model bridged the students' different language abilities.

Third, when the inequalities were modeled with more than one tool, the physical things, the line segments, and languages of different types, the students could reflect on the relationships among numbers instead of producing a numerical answer. The students were able to reflect not only on visible aspects regarding additive and multiplicative relationships within the numbers - for example, that the same quantity can be represented by equal length models - but also on invisible aspects such as instantly judging that two quantities can be equal despite the fact they are not positioned in the 
same way. The grade 1 students were also able to reflect on the issue that dividing a whole is sometimes only possible to do theoretically (cubes versus line segments).

Fourth, when the students used the combinations of the different tools, they were able to initiate a discussion on aspects of numbers that challenge them. Contradictions such as that the same quantity of objects (cubes) can be placed in different ways and still be of the same quantity could be evoked by the students.

\section{Concluding remarks}

The main results of this study indicate that young, newly arrived students, through tool-mediated joint reflective actions as suggested in the ED curriculum, succeeded in analysing arithmetical structures of positive integers and rational numbers. Structures in arithmetic are challenging to young learners: not only to second language learners but also to many young students (Adler, 2019; Campbell et al., 2007; Hansson, 2012). However, these types of joint action apparently succeed in mediating mathematical concepts and visualising tacit mathematical aspects of joint actions that, for example, Adler (2001) and Storch (2017) argue are of importance when teaching mathematics in multilingual classrooms. Actions like these can be interpreted as algebraic thinking (Bourbaki, 1974; Krutetskii, 1976) when the relationships between quantities were analysed with the use of algebraic symbols and line segment models instead of numerical examples only (cf., i.e., Blanton et al., 2019; Kaput, 2008; Kieran, 2018; Kieran et al., 2016). Thus, the students managed to identify some general structures in the given material and symbolic problem situation (cf., i.e., Adler, 2019; Campbell et al., 2007; Moxhay, 2008; Norén, 2015). The general structures were identified through symbols and models and developed as relationships. From this, it is possible for the students to analyse and understand numerical examples, thus opening up for what Davydov suggests as ascending from the abstract to the concrete. Further, the joint elaborative situations that were made available through the tasks suggested by the ED curriculum have the potential to establish what Norén (2015) regards as a common experience aimed at bridging different languages and different previous experiences related to mathematics among students. As mentioned earlier, almost all the students in this study were not familiar with mathematical concepts, either in Swedish or in their respective mother tongues; however, the joint and public use of the learning models seemed to mediate and make the object of knowledge transparent for the students to act on. The student learning actions comprised verbal language, line segment models, algebraic symbols, physical artefacts, and gestures which all together helped them to identify the structures of numbers as additive and multiplicative relationships.

One implication for teaching, indicated by this study, is that realising a learning activity inspired by the ED curriculum offers opportunities to bridge language obstacles in a multilingual classroom without giving up qualified mathematical content. This in turn creates rich opportunities for bridging tensions in relation to language demands in the multilingual classroom. Finally, we argue that the joint and public modeling of the learning models expanded the students' different language abilities. However, there is still a need for further empirical studies in which these learning models and their use in whole-classroom situations are explored in different cultural settings.

Acknowledgements We thank the teachers and students who helped us explore learning activity the ED curriculum. In addition, we thank Borlänge Municipality and Dalarna University for funding the study.

Funding Open access funding provided by Stockholm University. 
Open Access This article is licensed under a Creative Commons Attribution 4.0 International License, which permits use, sharing, adaptation, distribution and reproduction in any medium or format, as long as you give appropriate credit to the original author(s) and the source, provide a link to the Creative Commons licence, and indicate if changes were made. The images or other third party material in this article are included in the article's Creative Commons licence, unless indicated otherwise in a credit line to the material. If material is not included in the article's Creative Commons licence and your intended use is not permitted by statutory regulation or exceeds the permitted use, you will need to obtain permission directly from the copyright holder. To view a copy of this licence, visit http://creativecommons.org/licenses/by/4.0/.

\section{References}

Adler, J. (2001). Teaching mathematics in multilingual classrooms. Dordrecht, the Netherlands: Kluwer Academic Publishers.

Adler, J. (2019). Learning about mathematics teaching and learning from studying rituals and ritualization? A commentary. Educational Studies in Mathematics, 101(2), 291-299.

Arievitch, I. M., \& Stetsenko, A. (2000). The quality of cultural tools and cognitive development: Gal'perin's perspective and its implications. Human Development, 43(2), 69-92.

Bakhtin, M. M. (1981). The dialogic imagination: Four essays. Austin, TX: University of Texas Press.

Blanton, M., Stephens, A., Knuth, E., Gardiner, A., Isler, I., \& Kim, J. (2019). The development of children's algebraic thinking: The impact of a comprehensive early algebra intervention in third grade. Journal for Research in Mathematics Education, 46(1), 39-87.

Bourbaki, N. (1974). Elements of mathematics. Algebra 1. Great Britain: American Mathematical Society.

Campbell, A., Adams, V., \& Davis, G. (2007). Cognitive demands and second-language learners: A framework for analysing mathematics instructional contexts. Mathematical Thinking and Learning, 9(1), 3-30.

Carraher, D., \& Schlieman, A. (2007). Early algebra and algebraic reasoning. In F. Lester (Ed.), Second handbook of research on mathematics teaching and learning (pp. 669-706). Charlotte, NC: Information Age.

Davydov, V. V. (1975). The psychological characteristics of the "prenumerical" period of mathematics instruction. In L. P. Steffe (Ed.), Children's capacity for learning mathematics. Soviet studies in the psychology of learning and teaching mathematics (vol. VII, pp. 109-205). Chicago, IL: University of Chicago.

Davydov, V. V. (1982). The psychological characteristics of the formation of elementary mathematical operations in children. In T. Carpenter, J. Moser, \& T. Romberg (Eds.), Addition and subtraction. A cognitive perspective (pp. 224-238). Mahwah, NJ: Lawrence Erlbaum Associates, Inc., Publishers.

Davydov, V. V. (1990). Types of generalization in instruction: Logical and psychological problems in the structuring of school curricula. In Soviet Studies in Mathematics Education, 2 (Trans. Joan Teller). Reston, VA: National Council of Teachers of Mathematics.

Davydov, V. V. (2008). Problems of developmental instruction. A theoretical and experimental psychological study. New York: Nova Science Publishers, Inc..

Davydov, V. V., Gorbov, S. F., Mikulina, G. G., \& Saveleva, O. V. (2012). Matematikka 1 and 2. Moscow, Russia: VitaPress.

Davydov, V. V., Slobodchikov, V. I., \& Tsuckerman, G. A. (2003). The elementary school student as an agent of learning activity. Journal of Russian and East European Psychology, 41(5), 63-76.

El'konin, D. (1999). On the structure of learning activity. Journal of Russian \& East European Psychology, 37(6), 84-92.

Eriksson, H. (2015). Rationella tal som tal. Algebraiska symboler och generella modeller som medierande redskap. [Rational numbers as numbers. Algebraic symbols and general models as mediated tools.]. Stockholm, Sweden: Department for Mathematics and Science Education.

Eriksson, I., Wettergren, S., Fred, J., Nordin, A.-K., Nyman, M., \& Tambour, T. (2019). Materialisering av algebraiska uttryck [Materialising algebraic expressions]. Nordic Studies in Mathematics Education, 24(34), 81-107.

Freudenthal, H. (1975). Soviet research on teaching algebra at the lower grades of the elementary school. Educational Studies in Mathematics, 5(4), 391-412.

Giest, H., \& Lompscher, J. (2003). Formation of learning activity and theoretical thinking in science teaching. In A. Kozulin, B. Gindis, V. Ageyev, \& S. Miller (Eds.), Vygotsky's educational theory in cultural context (pp. 267-288). Cambridge, UK: Cambridge University Press.

Gorbov, S. F., \& Chudinova, E. V. (2000). The effect of modelling on the students' learning (regarding problem formulation). Psychological Science and Education, 2, 96-110. 
Gutierrez, A., Leder, G., \& Boero, P. (Eds.). (2016). The second handbook of research on the psychology of mathematics education. Rotterdam, the Netherlands: Sense Publishers.

Hansson, A. (2012). The meaning of mathematics instruction in multilingual classrooms: Analysing the importance of responsibility for learning. Educational Studies in Mathematics, 81(1), 103-125.

Izsák, A., \& Beckmann, S. (2019). Developing a coherent approach to multiplication and measurement. Educational Studies in Mathematics, 101(1), 83-103.

Kaput, J. (2008). What is algebra? What is algebraic reasoning? In J. Kaput, D. W. Carraher, \& M. Blanton (Eds.), Algebra in the early grades (pp. 5-17). Mahwah, NJ: Lawrence Erlbaum.

Kieran, C. (2018). Teaching and learning algebraic thinking with 5-to 12-years-olds. In In The global evolution of an emerging field of research and practice. Hamburg, Germany: Springer International Publishing AG.

Kieran, C., Pang, J., Schifter, D., \& Fong Ng, S. (Eds.). (2016). Early algebra. Research into its nature, its learning, its teaching. Switzerland: Springer International Publishing AG.

Krutetskii, V. (1976). The psychology of mathematical abilities in school children. Chicago, IL: University of Chicago Press.

Lantolf, J., \& Zhang, X. (2017). Concept-based language instruction. In S. Loewen \& M. Sato (Eds.), The Routledge handbook of instructed second language acquisition (pp. 146-166). New York, NY: Taylor \& Francis.

Leont'ev, A. N. (1978). Activity, consciousness, and personality. Englewood Cliffs: Prentice-Hall.

Morris, A. K. (2000). A teaching experiment: Introducing fourth graders to fractions from the viewpoint of measuring quantities using Davydov's mathematics curriculum. Focus on Learning Problems in Mathematics, 22(2), 32-83.

Moxhay, P. (2008). Assessing the scientific concept of number in primary school children. In Paper presented at International Society for Cultural-historical Activity Research. Los Angeles, CA: ISCAR.

Norén, E. (2015). Agency and positioning in a multilingual mathematics classroom. Educational Studies in Mathematics, 89(2), 167-184.

Radford, L. (2014). The progressive development of early embodied algebraic thinking. Mathematics Education Research Journal, 26(2), 257-277.

Radford, L. (2015). The epistemological foundations of the theory of objectification. In Isonomia (pp. 127-149). http://isonomia.uniurb.it/epistemologica. Accessed Feb 2018

Repkin, V. (2003). Developmental teaching and learning activity. Journal of Russian and East European Psychology, 41(5), 10-33.

Roth, W.-M., \& Radford, L. (2011). A cultural-historical perspective on mathematics teaching and learning. Rotterdam: Sense Publishers.

Roth, W.-M., \& Radford, L. (2011). A cultural-historical perspective on mathematics teaching and learning. Rotterdam, the Netherlands: Sense Publishers.

Schmittau, J. (2003). Cultural-historical theory and mathematics education. In A. Kozulin, B. Gindis, V. Ageyev, \& S. Miller (Eds.), Vygotsky's educational theory in cultural context (pp. 225-246). Cambridge, UK: Cambridge University Press.

Schmittau, J. (2011). The role of theoretical analysis in developing algebraic thinking: A Vygotsian perspective. In J. Cai \& D. Knuth (Eds.), Early algebraization:A global dialogue from multiple perspectives (pp. 71-85). Berlin, Germany: Springer.

Storch, N. (2017). Sociocultural theory in the L2 classroom. In S. Loewen \& M. Sato (Eds.), The Routledge handbook of instructed second language acquisition (pp. 69-85). New York, NY: Taylor \& Francis.

Venenciano, L., \& Heck, R. (2016). Proposing and testing a model to explain traits of algebra preparedness. Educational Studies in Mathematics, 92(1), 21-35.

Vetenskapsrådet [The Swedish Research Council]. (2017). God forskningssed [Good research practice].

Vygotsky, L. (1978). Mind in society: The development of higher psychological processes. Cambridge: Harvard University.

Warren, E., Trigueros, M., \& Ursini, S. (2016). Research on the learning and teaching of algebra. In Á. Gutiérrez, G. Leder, \& P. Boero (Eds.), The second handbook of research on the psychology of mathematics education. The journey continues (pp. 73-109). Rotterdam/Boston//Taipei: Sense Publisher.

Yeong, J., \& Dougherty, B. (2013). Linking multiplication models to conceptual understanding in measurement approach. $11^{\text {th }}$ Hawaii Conference of Education. Honolulu: HI.

Zuckerman, G. (2004). Development of reflection through learning activity. European Journal of Psychology of Education, $X I X(1), 9-18$.

Publisher's note Springer Nature remains neutral with regard to jurisdictional claims in published maps and institutional affiliations. 